\title{
El proceso de discusión de la Ley Federal de Radio, Televisión y Telecomunicaciones en el contexto de la Teoría de la Acción Social
}

\author{
María de la Luz Casas Pérez* \\ instituto Tecnológico y de Estudios Superiores de Monterrey, \\ Campus Cuernavaca
}

El papel de los medios de comunicación es vital para comprender la forma en la que se desarrollan las agendas de la discusión en cualquier sistema social. Sin embargo, poco se ha estudiado la forma en que los actores sociales se presentan ante la opinión pública a fin de promover su causa e incidir en un tema específico. La manera en la que éstos se articulan y presentan en el escenario social, resulta sustantiva tanto para los objetivos de su acción así como para el establecimiento de su importancia relativa dentro de un escenario político.

Las transformaciones recientes de los procesos de gestión de las políticas públicas del audiovisual, sugieren la necesidad de estudiar la participación de los diversos actores que intervinieron en el proceso de discusión de las reformas a la Ley de Radio y Televisión y de Telecomunicaciones, así como su incidencia en los medios periodísticos impresos.

Palabras clave: Teoría de la Acción Social, Ley Federal de Radio, Televisión y Telecomunicaciones.

\footnotetext{
* Licenciada en Ciencias de la Comunicación, Maestra en Comunicación y Doctora en Ciencia Política. Investigador Nacional Nivel 2. Profesora-investigadora del Tecnológico de Monterrey, Campus Cuernavaca en la División Académica de Profesional y Posgrado, e investigadora asociada en el Centro de Investigación en Información y Comunicación (CINCO) en el Tecnológico de Monterrey, Campus Monterrey. La autora desea agradecer la colaboración de los alumnos Rosita Padilla, José Guadalupe Mondragón y Claudia Galeana en la elaboración de este trabajo. Correo electrónico: marilu.casas@itesm.mx
} 
The role of communication media is vital to understand the development of discussion topics in any social system. Nevertheless, not enough has been studied in the way social actors present themselves to public opinion in order to promote their cause and influence a specific subject. The way in which these are articulated and presented in the social scenery, is important both to the objectives of their action, as well as for the establishment of its relative importance within a politics scenario.

Recent transformations in the achievement of audiovisual public policy decisions, suggest the need to study the participation of different actors that intervened in the discussion process of the reforms on the Mexican Radio, Television and Telecommunications Law, as well as its impact on the printed media

Key words: Social Action Theory, Mexican Radio, Television and Telecommunications Law.

\section{INTRODUCCIÓN}

Frecuentemente olvidamos que los grupos sociales somos consecuencia de las relaciones que establecemos entre individuos y que la sociedad es el producto de la construcción de sujetos en permanente interacción.

Durante mucho tiempo una buena parte de las teorías de la comunicación social se enfocaron al análisis de los productos o las manifestaciones de la comunicación, conocidas también como efectos de los mensajes. El énfasis de los estudios basados en estas teorías se centraba, en gran medida, en la operación del amplio espectro de medios que en su momento fueron llamados medios de comunicación masiva; no obstante, el avance teórico del campo de la comunicación dejó atrás algunas consideraciones sustantivas de las teorías sociológicas que les dieron origen, es decir de la base sustantiva que pretende explicar el fundamento esencial de la acción individual y colectiva que es la que finalmente nos orienta hacia la comunicación. En otras palabras, sin tomar en consideración las respuestas que como sujetos efectuamos a partir de los mensajes que recibimos son, en gran medida, resultantes de la valoración que hacemos de quienes los envían. La estructura de relaciones que los individuos y los grupos establecemos a partir de los mensajes que enviamos y recibimos se encuentra altamente condicionada por las relaciones que demarcan esa estructura y que es la que finalmente define las condiciones de nuestra interacción y la forma en que esa interacción nos articula como miembros del todo social. 
El presente trabajo responde a la necesidad de ver a la comunicación no solamente como el complejo entramado de información, mensajes y reacciones a dichos mensajes, sino como la manifestación de condiciones de relación previamente establecidas y que orientan las manifestaciones simbólicas indirectas de dicha vinculación entre los sujetos.

La premisa fundamental que anima la reflexión teórica para este estudio radica en recordar que la forma en la que se articulan las condiciones políticas y económicas de los fenómenos no es sino una resultante indirecta de la existencia de ciertas formas de articulación social. Esto es, la comunicación y las manifestaciones directas o indirectas de la comunicación que pueden o no manifestarse a través de medios masivos, son consecuencia de vinculaciones establecidas previamente entre individuos y grupos así como de las formas de rearticulación que se establecen a partir de la lucha por definir continuamente las condiciones de dichas relaciones.

En el caso que aquí nos ocupa, nos interesa analizar un proceso concreto de discusión hacia la definición de una política pública específica que es el proceso de discusión de la Ley Federal de Radio y Televisión y Telecomunicaciones, tal y como se ha dado en los últimos meses, a partir no del análisis histórico documental y de definición de sus términos, sino a partir de los procesos de interacción de aquellos actores que se encuentran involucrados en su definición. Nos interesa, además, reconocer cómo es que los propios medios de comunicación, particularmente aquellos que han dejado huella del proceso, han registrado los diferentes momentos en que se ha llevado a cabo dicha interacción. Nuestro propósito es generar un esquema básico de referencia que pueda utilizarse en el análisis de una parte del todo social y que nos permita dilucidar con mayor precisión la forma en que la que se producen varios procesos yuxtapuestos; por un lado la discusión, y gestión política -entendida claramente como una lucha por el poder-, la articulación de argumentaciones que definen y presentan las distintas posturas de actores sociales y políticos y la manera en que los medios las recogen y, por último, la forma en que dichas posturas y tomas de posición de los actores se ponen de manifiesto ante la opinión pública con la finalidad de influir en la gestión de políticas públicas, desde la teoría de la acción social.

Para tal efecto, por tanto, en este trabajo se analizará a los actores sociales, políticos y económicos que se han puesto de manifiesto en el proceso reciente de discusión de la Ley Federal de Radio, Televisión y Telecomunicaciones, así como la forma en que dichas manifestaciones se han presentado ante la opinión pública en un período muy específico que va de la fecha en la que se aprueba la

\author{
El proceso de discusión de la Ley Federal de Radio, Televisión • 39 \\ y Telecomunicaciones en el contexto de la Teoría de la Acción Social
}


llamada Ley Televisa en abril del 2006, hasta la fecha en que la Suprema Corte de Justicia de la Nación declara inconstitucionales algunos de sus preceptos en $2007 .^{1}$

Nuestra intención es generar la discusión y el análisis de este tema que resulta central para la estructura y operación de los medios audiovisuales en México, desde el análisis de escenarios y a partir de un panorama de la forma en que los diferentes actores se han presentado ante la opinión pública para la discusión de este fenómeno, mostrando que el proceso de gestión de política pública se da en realidad en dos niveles aparentemente inconexos pero claramente vinculados, a saber, el de la lucha por el poder y la discusión política, y el de la apropiación de los espacios en los medios. Uno subsume al otro, pero al igual que en un escenario no existe la posibilidad de continuar la acción si el reflector no se encuentra bien colocado e iluminando claramente al actor que será el siguiente en turno para darle continuidad a la trama.

En el caso de la discusión sobre la ley de medios electrónicos y telecomunicaciones que aquí nos ocupa, veremos cómo es que cada uno de los actores ha colocado en un momento dado su argumento en un espacio del escenario que no necesariamente puede ser visto por todos los espectadores de la opinión pública, de tal suerte que la discusión se ha perdido para volverse a retomar posteriormente con otras condiciones que han perdido o debilitado el argumento esencial.

A partir de este trabajo no podemos sino sugerir que la perspectiva macro, por tanto, el resultado de las acciones de los diferentes actores se convierte en un subproducto de sus relaciones en el nivel micro y que, por tanto, la argumentación y la definición de una gestión pública no puede sino entenderse a partir de entender las reglas y los mecanismos que rigen la discusión y la argumentación que, en mucho, se encuentran previamente definidos por la posición relativa de los actores en el escenario. Esta perspectiva constituye una propuesta para entender la discusión y la gestión social de políticas públicas a través de la teoría de la acción social.

\footnotetext{
${ }^{1}$ Acuerdo del Tribunal Pleno de la Suprema Corte de Justicia de la Nación, correspondiente al día 23 de agosto de 2007 y publicado en el Diario Oficial de la Federación el 19 de octubre de 2007. Para fines de este trabajo, los datos recogen las declaraciones periodísticas hechas exclusivamente a medios impresos durante este período.
}

40 - María de la Luz Casas Pérez 


\title{
LA TEORÍA DE LA ACCIÓN SOCIAL
}

La interacción social ha sido considerada como uno de los pilares de la sociología contemporánea. Su propósito fundamental ha sido la descripción del orden, a fin de entender a la sociedad como el producto de la interacción, de los intereses o de las motivaciones de los individuos y de los grupos.

Si bien la tradición sociológica establece como la base de la acción social a aquellas conductas significativas con repercusiones de índole colectivo cuyas manifestaciones se definen a partir de éstas (Weber, 1977), (Durkheim, 1964), la teoría de la acción social no es solamente un subproducto de la interpretación del orden social sino también de su reproducción y mantenimiento. Así pues, la teoría de la acción social se ha vinculado también con el estructural-funcionalismo de Parsons (1951) o de Merton (1968), e incluso con el interaccionismo simbólico en el que puede ubicarse a Goffman (1959) o Alexander (1983). Giddens (1984) incluso considera el concepto de la acción social como elemento esencial de cohesión y al actor social como fundamento de la estructuración social. Ya en una perspectiva más reciente, tanto Touraine (1977) como Luhmann (1988 y 1990) considerarán a la producción social o a aquello que se establece como condición autorreferenciada productora de sentido, como índices consustanciales relativos a la articulación y reproducción social.

En el sentido weberiano, la acción social se entiende como una conducta humana con sentido y dirigida a la acción de otro. De manera que la acción social se reviste de un sentido esencialmente humano pues busca no solamente expresar sino también un actuar sobre otro, lo cual le imprime un sentido eminentemente comunicativo y social. Ahora bien, el propio Weber entiende que si bien toda acción de un individuo se encuentra revestida de pensamiento y valores adquiridos, también se encuentra en relación directa a los medios utilizados y a los fines perseguidos. En este sentido y para el propósito de este trabajo, nosotros entenderemos que los actores que han venido entrando en interacción en las distintas fases de discusión de la política pública (léase la promulgación de la Ley Federal de Radio, Televisión y Telecomunicaciones y de su replanteamiento), han tenido como finalidad específica argumentar a favor o en contra de la ley, o bien a favor o en contra de una nueva ley de medios, de manera que la expresión de esta argumentación a partir de su presentación en los medios (en este caso medios impresos), tiene como fin específico o bien proponer una postura, o bien influir al otro.

Según Weber las acciones básicas que un actor puede ejecutar emanan de

\author{
El proceso de discusión de la Ley Federal de Radio, Televisión • 4I \\ y Telecomunicaciones en el contexto de la Teoría de la Acción Social
}


precondiciones básicas en las cuales puede prevalecer: a) la acción racional de acuerdo a fines, b) la acción racional de acuerdo a valores, c) la acción afectiva, d) la acción relacional. En la primera el sujeto argumenta racionalmente pretendiendo expresar condiciones y fundamentaciones lógicas de su acción; en la segunda, el móvil principal es la defensa a ultranza de los valores independientemente de las consecuencias; en la tercera se responde a sentimientos afectivos, positivos o negativos según sea el caso, mientras que en la cuarta se aducen valores tradicionales de tipo social.

Ahora bien, tanto actuantes como receptores de la acción condicionan su relación a partir de la actividad del otro, de manera que a mayor sea el número de actores o receptores mayor complejidad habrá en el entramado social y tanto más difícil será predecir los escenarios posibles producto de esa interacción. Por otra parte, tanto los actores como los receptores pueden ser individuos o grupos, de manera que en ocasiones la interacción puede darse de individuo a individuo, de individuo a grupo, de grupo a individuo, o de grupo a grupo.

Ahora bien, desde el interaccionismo simbólico Goffman define la acción social como aquella actividad en la que se desempeña un rol. El apego a un rol normalmente se define como una situación estable o consistente ya sea, con la imagen que uno tiene de sí mismo, o con un determinado papel asignado por la sociedad. En este sentido, la prestación concreta de un rol se considera mera consecuencia de: a) el modelo normativo de rol, b) el rol típico, y c) la prestación o ejecución de un rol (Linton, 1936, pp. 83-92 en Herrera y Soriano, 2004, p. 65).

Lo anterior nos lleva a suponer que las declaraciones que un determinado actor proporciona a la prensa, por ejemplo, no corresponden de manera íntegra a la voluntad o deseo de expresión individual de ese actor, sino que de alguna medida éste se siente obligado a expresarlas en estricto apego a la ejecución de un rol. En este mismo sentido Goffman expresa por ejemplo que los roles estructurales que los sujetos tienen que desempeñar en instituciones, se encuentran definidos en términos de expectativas y sanciones, y que cualquier rol se define como comportamiento dentro de un conjunto de otras actividades (Goffman, 1961, p. 96). De tal manera que el comportamiento del individuo transformado en actor social o político, siempre será algo más que un hecho incidental; antes bien, se debe interpretar en términos de su pertenencia a una institución en cuanto tal, de la ubicación de su jerarquía y de lo esperado de éste en términos de la normatividad o formalización de su rol. "Asumir un rol significa ser subsumido por éste" (Goffman, 1961, p. 106). 
Ahora bien, como individuos ejecutamos una variedad de roles dependiendo de la necesidad funcional del rol en su vinculación con otros, por ejemplo: para que exista el rol de víctima, tiene que existir el rol de victimario. De esta manera Goffman enlaza la acción individual a la acción colectiva, ya que la expresión y representación de ciertos roles aparece en función de las formas de organización social. Estas formas preferentes de organización social han sido definidas por algunos autores como marcos referenciales o frames. El framing permite que dentro del escenario y ante la ejecución de los diversos autores el espectador pueda definir la orientación de un comportamiento de manera consecuente con la expresión de un rol. En este aspecto es que la teoría de la acción social y el interaccionismo de Goffman se relaciona con el estructural funcionalismo de Parsons, en tanto que éste último desarrolla una serie de variables estructurales que le permiten conocer y comprender los diferentes tipos de acciones y roles sociales (Parsons, 1951), y éste último desde la teoría de sistemas se vincula directamente con la expresión de una determinada acción social desde las formas del lenguaje Goffman, (1981), la acción discursiva de Van Dijk, (1985, 1999) o la autopoiesis de Luhmann (2005). En este sentido la definición de los actos sociales tiene un correlato comunicativo en el sentido de la dimensión ritual de la comunicación y las características específicas que asume dependiendo del estatus de quienes interactúan, de sus relaciones, de su ideología manifiesta o encubierta, y de los contextos culturales o sociales en los que lo hacen.

Ahora bien, en el caso que aquí nos ocupa, una cosa es la declaración que un determinado actor político hace, y otra la que el medio recoge. El actor político puede buscar ponerse en el reflector a fin de lograr visibilidad ante los medios, pero el medio también puede destacar aspectos esenciales de su declaración de acuerdo con su línea editorial u orientación ideológica. El proceso de construcción de la noticia ha sido desde luego estudiado por McCombs y Shaw (1972), Gitlin (1980), Rodrigo Alsina (1989), Tuchman (1983) y Verón (1995), quienes han enfatizado el papel que juega el medio y el reportero en la selección de los acontecimientos que lograrán la visibilidad periodística.

No obstante lo anterior y en concordancia con los conceptos de asunción de rol y distancia de rol enunciados por Goffman, en los que un determinado actor exhibe una distancia respecto de la asunción social de un rol, se presenta funcionalmente con respecto a su rol pretendiendo mostrarse como consciente y eficaz o administra las tensiones propias de su rol de tal manera que administre su papel tal y como un actor lo hace en un performance ante el público (Goffman, 1961, pp. 96-133), nosotros consideramos que, independientemente de lo que

El proceso de discusión de la Ley Federal de Radio, Televisión $\bullet 43$ y Telecomunicaciones en el contexto de la Teoría de la Acción Social 
desde el punto de vista del medio pueda constituir el criterio periodístico desde el cual se elige o se privilegia la difusión de un acontecimiento, la visibilidad de un actor político puede estar también determinada por:

a) la preferencia de un determinado actor a presentarse ante un medio

b) la preferencia de un medio a cubrir a un determinado actor político debido a su importancia, notoriedad o "explosividad" de sus declaraciones

c) la institucionalidad de un actor que busca que el medio lo cubra para reforzar su posición política

d) la necesidad de un actor político de hacer una declaración acorde con lo que se espera de él de acuerdo con su rol.

De esta forma, reconocemos que la representación de un rol por parte de un actor político implica e integra también los conceptos de "fachada", representación en escena, expresión entre bastidores, rol, distancia de rol y otros, que el propio Goffman tomó de Bateson (1972) al desarrollar el concepto de frame. (Goffman, 1974, pp. 11-12). En este sentido la expresión del actor se convierte en un marco viable para la interpretación, ya que "lo importante no es cómo se presenta la realidad exterior, sino cómo es interpretada" (Goffman en Sebastián, 1994, p. 3). Esta categorización refleja una relación entre la acción y la situación que se asemeja a la teoría general de la acción parsioniana cuyo propósito es comprender los diferentes tipos de acciones y roles sociales dependiendo del análisis sistemático de las "definiciones de la situación" que enmarcan tales acciones y situaciones, confiriéndoles determinado significado social. (Manning, 1992, p. 118). Lo anterior no implica que un determinado actor ejecute una desviación permanente de un rol, con el propósito de confundir a su interlocutor respecto de la originalidad o veracidad de su interpretación; antes bien, tanto Goffman como Parsons señalan que esta representación constituye una interpretación genuina de los modelos y esquemas fundamentales que los individuos asumen como base relativamente estable de su representación de la realidad. (Goffman, 1981, p. 108), de tal suerte que la interiorización de los valores de los sujetos a través de su representación por medio de la comunicación y como consecuencia de la acción, constituyen la fuerza esencial necesaria para la interpretación de las normas que rigen al todo social. La acción social, por tanto, se constituye en representación de los valores que la sociedad determina como importantes y el actor en la figura de enlace entre él, como representación de dichos valores, y su receptor o público.

44 - María de la Luz Casas Pérez 
Nuestra premisa fundamental es que, si el actor se manifiesta y los medios de comunicación recogen esa expresión, podemos estar ante una auténtica representación de un acontecimiento social ante el cual se ponen de manifiesto diversas posturas por constituir éste un hecho de relevancia o preocupación social. El asunto pues se presenta como la puesta en escena de una multiplicidad de actores, cada uno buscando la luz lo de los reflectores a fin de exponer su parte ante una opinión pública que ocuparía el papel de público receptor. En el caso que aquí nos ocupa, no estaríamos atendiendo a las interpretaciones diversas que ésta opinión pública derivaría como consecuencia de dicha presentación, sino exclusivamente a las condiciones originales de la puesta en escena.

\section{EL TÍTULO DE LA OBRA Y LOS ACTORES}

El título de la obra en este caso es la discusión de la viabilidad de la Ley Federal de Radio, Televisión y Telecomunicaciones, aprobada en abril de 2006, conocida como Ley Televisa. El marco temporal de la obra va, desde finales de 2005 en que se preveía la posibilidad de la modificación de la ley anterior, ${ }^{2}$ el conjunto de las declaraciones y la apelación por parte de los actores inconformes, hasta la resolución de inconstitucionalidad de la Suprema Corte de Justicia de la Nación en agosto del 2007.

Los actores de esta obra, son todos los sujetos que a título personal, institucional o como profesionales de algún medio de comunicación reportaron sobre este acontecimiento.

Si se nos permite una crítica al desempeño actoral de los participantes, diremos que durante el lapso aquí reportado cada uno de ellos pretendió encender su reflector lo más posible, enfatizando la calidad y trascendencia de su actuación, no necesariamente favoreciendo con ello la claridad de su argumento.

La crítica, si es que podemos tomar esta analogía, para referirnos a lo que los medios de comunicación reportaron sobre el particular, se centró en el protagonismo de los actores y en la contundencia de sus expresiones más que en la profundidad de la temática. Nosotros, como observadores externos a toda la representación, por el momento solamente nos enfocaremos a lo que sucedió en el escenario y a lo que los críticos expresaron momentos después de la puesta en escena, no así a las opiniones de quienes asistieron a ella.

${ }^{2}$ Ley Federal de Radio y Televisión de 1960.

El proceso de discusión de la Ley Federal de Radio, Televisión $\bullet 45$ y Telecomunicaciones en el contexto de la Teoría de la Acción Social 
La obra continúa; sin embargo ya que por el momento sólo conocemos lo que sucedió en el transcurso de ese período de tiempo, pero todavía no conocemos el desenlace. Los espectadores de la obra es decir la opinión pública, por tanto, está en suspenso.

\section{CONSIDERACIONES METODOLÓGICAS}

Para fines de este estudio, la metodología empleada fue la siguiente:

El núcleo de la investigación fue el actor social, cuyas manifestaciones buscaron expresión y fueron recogidas a través de medios impresos de circulación nacional disponibles a través de recursos electrónicos (internet). De manera colegiada entre las personas que participaron en la investigación se definieron las características visibles de un actor social, así como sus expresiones y manifestaciones. A fin de recoger una clasificación pertinente para este estudio, el concepto de actor social, se subclasificó y operacionalizó de la siguiente manera:

\section{Actor social:}

Desde el punto de vista de la acción social, el concepto de actor puede ser visto como elemento esencial para la estructuración social (Giddens, 1984), como posibilidad de acción autoreferenciada (Luhmann, 1982, 1990), como elemento fundamental de la acción social (Parsons, 1937, 1988), o como articuladores de la producción social (Touraine, 1977).

Entendemos por actor a aquel sujeto, individuo o institución que participa con diferentes enfoques o niveles de participación. La característica de un actor social es lograr la transformación del entorno en el cual participa, ya sea a través de declaraciones, organización de eventos, liderazgo de grupos o cualquier otra manifestación de tipo social. Su incidencia puede traducirse en la transformación concreta de la realidad sobre la cual participa.

Las notas fueron clasificadas dependiendo del tipo de actor que las enunciaba, siendo la clasificación que se empleó la siguiente:

Educativo: Referido en general a personas que trabajan en una institución educativa o de investigación, especialmente en calidad de investigador, docente o académico. Su propósito es el análisis de la realidad social, aunque desde luego no se descarta cualquier filiación política o partidista.

Empresarial: Pertenece al ámbito empresarial o productivo. Se interesa por transformar el estado de cosas que guarda la economía o la relación de los 
actores económicos entre sí. Puede tratarse de sujetos que hablan a título personal pero que cuentan con un liderazgo importante en el ámbito empresarial o productivo, o bien de personas que hablan a título de las empresas que representan.

Institucional: Se trata de un funcionario o representante de una institución que habla a nombre de ella o en su calidad de experto o máxima autoridad. La institución en cuestión puede ser de naturaleza privada o pública, pero no necesariamente representando los intereses de una organización productiva.

Mediático:Se trata de un representante de un medio de comunicación que habla, reportando sobre el acontecimiento o bien comentando acerca de él. Ejemplo: reportero, articulista, editorialista.

Político: Se trata de funcionarios públicos, legisladores, militantes o dirigentes de partidos políticos, o bien de grupos que buscan promover una postura ideológica o política concreta. También pueden aparecer categorizados en este rubro personalidades que tienen o han tenido trascendencia en el ámbito político.

Social/cultural: Por definición todos los actores son actores sociales en tanto que influyen en el destino de la organización social, sin embargo dentro de la categoría de actor social/cultural nos referimos a personalidades que por su calidad humana, científica, académica o artística son reconocidos por la comunidad como sujetos de calidad íntegra. Aquí nos referimos a personajes que se constituyen como líderes natos por su participación en el ámbito social o cultural, cuya opinión es generalmente muy valorada y tomada en cuenta a nivel social.

La unidad de estudio fue el artículo periodístico. El periodo de observación se hizo entre diciembre del 2005 y diciembre del 2007 por considerar que en este período se llevaron a cabo acontecimientos importantes relativos a la discusión de la ley, la aprobación en la cámara, su promulgación en el Diario Oficial de la Federación y la discusión posterior que culminó en el dictamen de la Suprema Corte de Justicia de la Nación. La búsqueda se hizo en los registros electrónicos ubicados en las bases de datos Infolatina y Notimex que recaban

\author{
El proceso de discusión de la Ley Federal de Radio, Televisión $\bullet 47$ \\ y Telecomunicaciones en el contexto de la Teoría de la Acción Social
}


el compendio de las principales publicaciones periódicas nacionales. El corpus de investigación lo constituyeron todos los artículos publicados en ese período. Para la ubicación de notas se utilizaron buscadores de Internet en los que se ingresaron a la vez títulos claves que permitieron ubicar información de notas periodísticas relativas a la La Ley Federal de Radio, Televisión y Telecomunicaciones o Ley Televisa, siendo la muestra de 110 artículos.

El tipo de muestra no probabilística intencional o por juicio, entendida ésta como aquella en el que se busca la representatividad por apego a los criterios previamente definidos por el investigador para el objetivo de la investigación. ${ }^{3}$ Cada artículo fue leído cuidadosamente, identificado y seleccionado dependiendo del tipo de argumento expresado (a favor, en contra o neutral) con relación a la Ley de Radio, Televisión y Telecomunicaciones o Ley Televisa. Para la selección de esta muestra se buscó replicar la metodología de Tankard (1991, p. 5), buscando estandarizar los mecanismos de selección y de juicio entre los distintos evaluadores del material a fin de catalogar los distintos argumentos. Una vez identificados los diferentes actores, se registraron sus declaraciones, se clasificó su postura dependiendo de si se ubicaba a favor o en contra de la Ley Federal de Radio, Televisión o Telecomunicaciones, o si presentaba una posición neutral, y se procedió al conteo.

La selección de etiquetas de catalogación se hizo con base a variables específicas tales como tipo de actor, rango o título del declarante, tipo de declaración, si ésta fue hecha a título personal o no, la posición, el medio en el que apareció publicada y la fecha.

Los registros obtenidos fueron seleccionados de acuerdo con su relevancia y tomando en consideración que en el cuerpo de texto quedara clara la declaración atribuida a algún actor específico descartándose aquellas noticias en la que la mención a la ley fuese indirecta o tangencial.

Los artículos periodísticos que finalmente conformaron el corpus de la investigación y quedaron definidos como parte de la muestra, fueron aquellos en los que apareció un actor claramente identificado con una posición específica.

\footnotetext{
${ }^{3}$ Para el caso que nos ocupa, por tanto, se eliminaron todas aquellas notas periodísticas cuyo tratamiento fue exclusivamente informativo y se dejaron solamente aquellas en las que una declaración es atribuida de manera directa y explícita a un actor particular, ya sea a través de parafraseo, entrecomillado o cita textual.
} 


\section{Resultados}

Los resultados preliminares de esta investigación muestran claramente la forma en que los medios de comunicación recogen los planteamientos de los distintos actores políticos, siendo la mayoría de las participaciones pertenecientes a actores de naturaleza política, en segundo lugar a actores de tipo institucional, y en tercer lugar a actores de tipo empresarial (Cuadro 1). La participación de comentaristas/editorialistas aparece en cuarto lugar, seguida por actores de las instituciones educativas y en último lugar por miembros destacados de la sociedad.

Cuadro I

Distribución de notas por actor social

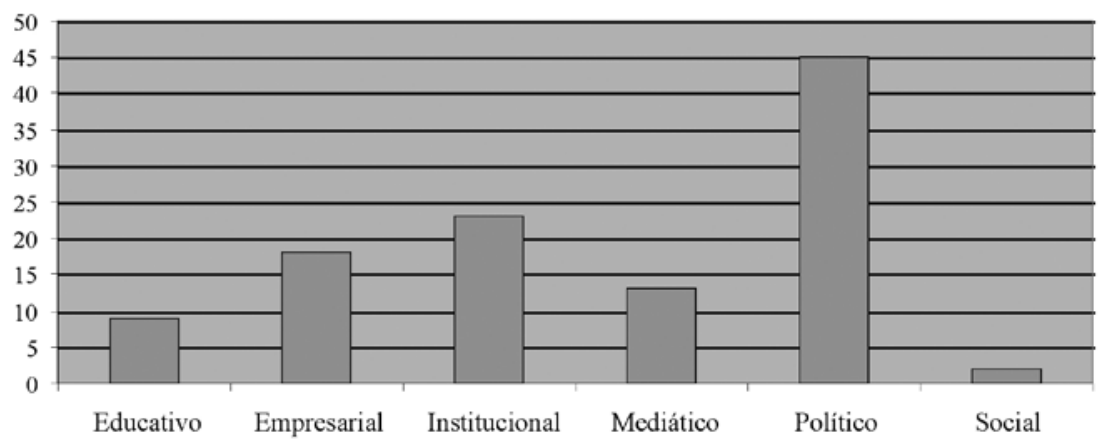

La presencia de actores mayoritariamente políticos y empresariales, refleja por un lado la práctica periodística tradicional de recoger predominantemente la opinión de quien ostenta un cargo de responsabilidad pública o de autoridad buscando de otra suerte contrastar sus posiciones, así como el reflector que los medios ponen sobre cierto tipo de actores. El Cuadro 2 permite señalar la posición relativa de cada uno de ellos con relación a este tema, lo cual lo ubica primordialmente como un tema de trascendencia política, con escasa participación por parte de actores de naturaleza educativa y social o cultural. Por su parte, los actores mediáticos se ubican en la parte intermedia con relación a su participación frecuentemente a través de columnas periodísticas o comentarios y ubicándose como auténticos mediadores entre los demás actores. Una buena parte de las declaraciones, especialmente aquellos de los actores políticos obtenidas por petición o presión de los reporteros; muchas de ellas son neutrales en concordancia con el carácter institucional del actor y con su decisión de no comprometerse con una postura específica, mientras que la mayor parte de las posiciones en contra son hechas a título personal, de manera que los lectores,

El proceso de discusión de la Ley Federal de Radio, Televisión 49 y Telecomunicaciones en el contexto de la Teoría de la Acción Social 
y en este caso la opinión pública, reciben una interpretación diferenciada de la información que seguramente recibirá diferente atención dependiendo del conocimiento o relevancia que se le otorgue al actor en cuestión.

El Cuadro 2 muestra la posición de las declaraciones y de una polarización manifiesta en donde, sin embargo, se privilegiaron aquellas expresiones de ataque a la ley:

Posición de los diferentes actores

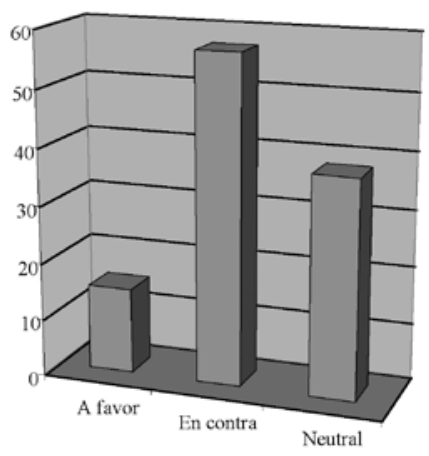

Número total de

expresiones: $11 \mathrm{C}$

Por otra parte, en atención a la práctica periodística tradicional, el Cuadro 3 muestra la ubicación temporal de las declaraciones, mostrando que el mayor número de expresiones relativos a la Ley Federal de Radio, Televisión y Telecomunicaciones se concentró o bien hacia finales del año 2005 previamente a su votación, o bien posteriormente a su aparición en el Diario Oficial de la Federación, o bien posteriormente a la determinación del fallo de la corte, siendo en este último momento en el que se ponen de manifiesto la mayor cantidad de las expresiones en contra.

\section{Cuadro 3}

\section{Ubicación temporal de las declaraciones}

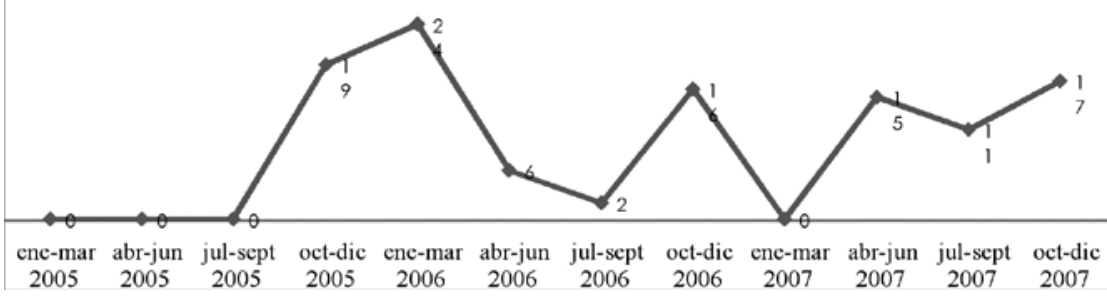

so - Maria de la Luz Casas Pérez 
En las fechas pico que marca la gráfica, la mayor parte de las expresiones de los actores son en contra de la ley o en todo caso a favor, generando así una predisposición, un frame o un marco de referencia para la opinión pública que privilegia la interpretación de este acontecimiento en este sentido.

El Cuadro 4 permite ver, por su parte, la frecuencia artículos periodísticos a favor, en contra y neutrales que publicaron los periódicos seleccionados dentro de la muestra.

\section{CuAdro 4}

Frecuencia de declaraciones en los medios

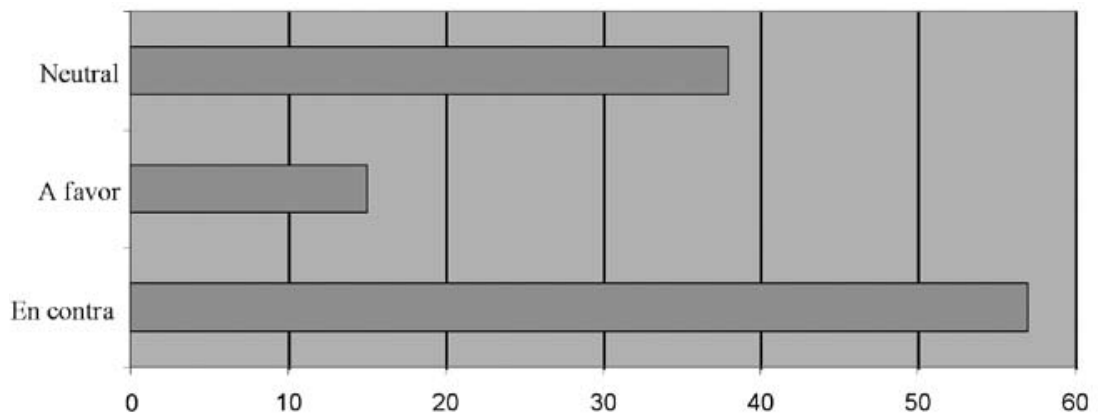

Lo anterior pudiera indicar que esta postura es favorecida en medios, ya sea porque la posición en contra es más fuerte que la posición a favor, porque los actores que defienden esta postura buscaron ser más visibles o bien porque la práctica periodística contemporánea privilegia las declaraciones de corte sensacionalista que aseguran la venta del periódico. ${ }^{4}$

Desde luego la mayor parte de las notas a favor o en contra fueron publicadas en periódicos cuya tendencia ideológica privilegiaba la postura del actor en cuestión. Los cuadros 5, 6 y 7 muestran el número de artículos correspondientes a cada posición, dependiendo del medio periodístico en el que aparecieron publicados. Así por ejemplo, el Reforma y el Financiero publicaron la mayor parte de las declaraciones a favor de la Ley Federal de Radio, Televisión y Telecomunicaciones, mientras que La Jornada publicó la mayor parte de las declaraciones en contra.

${ }^{4}$ Es necesario indicar también que una práctica periodística común es enfatizar cierto tipo de declaraciones por parte de un actor, lo cual no necesariamente puede reflejar adecuadamente la complejidad de su postura; no obstante el periódico la simplifica ubicándolo con ello dentro del escenario en una determinada posición.

El proceso de discusión de la Ley Federal de Radio, Televisión • $5 \mathrm{I}$ y Telecomunicaciones en el contexto de la Teoría de la Acción Social 
Cuadro 5

Articulos A FAVOR por medio de publicación

\begin{tabular}{|l|c|}
\hline Reforma & 4 \\
\hline El Economista & 2 \\
\hline El Universal & 2 \\
\hline La Jornada - Política & 1 \\
\hline Multimedios Estrellas de Oro & 1 \\
\hline Mural - Negocios & 1 \\
\hline Terra Networks México S.A. de C.V. & 1 \\
\hline El Financiero, Negocios & 2 \\
\hline Revista: Proceso & 1 \\
\hline TOTAL & 15 \\
\hline
\end{tabular}

Cuadro 6

Artículos EN CONTRA por medio de publicación

\begin{tabular}{|l|c|}
\hline Agencia de servicios integrales de comunicación, S.A. de C.V. & 2 \\
\hline Análisis Ediciones y Cultura - Etcétera & 1 \\
\hline Aregional - State News & 1 \\
\hline EFINFo (Eficiencia Informativa) antes México Analytica & 2 \\
\hline El Financiero - Cultura & 2 \\
\hline El Norte & 1 \\
\hline El Sol de México & 1 \\
\hline El Universal & 6 \\
\hline Grupo Empresarial Periodistico, SA de CV & 1 \\
\hline Infosel News & 1 \\
\hline La Jornada - Política & 10 \\
\hline Multimedios Estrellas de Oro & 2 \\
\hline Mural - Nacional & 2 \\
\hline Notimex - General & 3 \\
\hline Organización Editorial Mexicana & 2 \\
\hline Reforma & 8 \\
\hline Revista Mexicana de Comunicación & 1 \\
\hline Revista: Proceso & 3 \\
\hline Siempre & 2 \\
\hline Terra Networks México S.A. de C.V. & 6 \\
\hline TOTAL & 57 \\
\hline
\end{tabular}


Artículos NEUTRALES por medio de public

\begin{tabular}{|l|c|}
\hline Agencia de servicios integrales de comunicación, S.A. de C.V. & 2 \\
\hline Análisis Ediciones y Cultura - Etcétera & 2 \\
\hline Columna Rotafolio & 1 \\
\hline El Economista - Empresas y Negocios & 1 \\
\hline El financiero & 9 \\
\hline El Universal & 2 \\
\hline Infosel News & 2 \\
\hline La Jornada - Política & 2 \\
\hline Multimedios Estrellas de Oro & 2 \\
\hline Notimex - General & 5 \\
\hline Reforma & 6 \\
\hline Siempre & 2 \\
\hline Terra Networks México S.A. de C.V. & 2 \\
\hline TOTAL & 38 \\
\hline
\end{tabular}

Un desglose adicional, por tipo de actor demuestra que en sus declaraciones el actor es consistente con el tipo de declaración que se espera de él dependiendo de su posición institucional o ideología manifiesta. Así por ejemplo un actor que tradicionalmente opina en contra, o es considerado como tradicionalmente contestatario, va a ser publicado en periódicos con esa postura y viceversa; de tal forma las posiciones de actores institucionales y empresariales fueron tradicionalmente privilegiadas en periódicos de derecha, mientras que las posiciones de actores educativos y políticos fueron tradicionalmente privilegiadas en periódicos de izquierda.

Como se asentó previamente el número de expresiones en contra de la ley sobrepasó en número al número de expresiones a favor. Ahora bien, los actores que se hicieron más visibles en el escenario político, o pudiéramos decir recibieron mayormente la luz de los reflectores mediáticos y que tenían una posición institucional o política relevante para el caso en su momento, fueron: Javier Corral Jurado (Senador por Chihuahua), Carlos Sotelo García (Senador y Presidente de la Comisión de Radio, Televisión y Cinematografía), Manuel Bartlett Díaz (Senador por Puebla), Guillermo Ortíz Mayagoita (Magistrado y Presidente de la Suprema Corte de Justicia de la Nación) y Gerardo González Abarca (Comisionado de la Cofetel), la mayor parte de ellos con expresiones en contra de la ley o en todo caso, neutrales. La manifestaciones de las distintas expresiones del orden social por parte de los actores involucrados, da cuenta

El proceso de discusión de la Ley Federal de Radio, Televisión • 53 y Telecomunicaciones en el contexto de la Teoría de la Acción Social 
precisamente del interés y la necesidad de proporcionar, a través de una declaración, un punto de vista particular, defender una postura o presentar con base en argumentos un panorama de interpretación de un acontecimiento a todas luces de trascendencia social.

ANÁLISIS E INTERPRETACIÓN DEL SENTIDO DE LA ACCIÓN SOCIAL

Numerosos análisis y ensayos relativos a la discusión de la Ley Federal de Radio, Televisión y Telecomunicaciones se enmarcan dentro del ámbito de posturas de pertinencia y precisión, de los alcances y repercusiones de la ley, y de otros aspectos relacionados. Algunos de estos trabajos han sido precisamente recuperados por la prensa nacional y se encuentran contenidos en el período al que hacemos referencia; algunos más (Esteinou, Trejo, Alva de la Selva, Sosa Plata y otros), son parte de una comunidad académica que incluso ha buscado intervenir directamente en el proceso de gestación de políticas públicas en el sector (Alva de la Selva, 2008). No obstante, no ha habido un análisis de la discusión sobre la base de la acción social. Este trabajo pretende, precisamente determinar que todas aquellas expresiones, manifestaciones o interpretaciones sobre el particular son en sí mismas resultantes de la acción social. Si recordamos, la base de la acción social son aquellas conductas significativas con repercusiones de índole colectiva y trascendencia social. En este sentido las declaraciones de actores clave en la discusión acerca de la Ley Federal de Radio, Televisión y Telecomunicaciones, conocida como Ley Televisa, así como la interpretación y privilegio que de ellas hicieron los medios, resultan consustanciales para la discusión pública y para la resolución de un tema de trascendencia política y social. No obstante, estudiar la trascendencia de las informaciones y los argumentos publicados desde la teoría de la acción social implica un ir más allá del análisis de contenido que se focaliza sobre el simple conteo de los mensajes y su valoración, implica considerar al actor social como aquel individuo cuya acción transmite y comunica al mismo tiempo que contribuye a interpretar la realidad social como condición autorreferenciada productora de sentido, pero al que no hay que descartar como sujeto que ejerce una determinada acción con intereses particulares. Es decir, el actor social tiene como fin último político y comunicativo influir al otro o a los otros para con ese propósito afianzar su posición o su actuación dentro del escenario social. Así pues, siguiendo a Weber, sería necesario reflexionar en qué medida la acción social se define de acuerdo a fines, de acuerdo a valores, o de acuerdo a propósitos relacionales, al mismo tiempo que se cuestiona respecto 
de los sujetos objeto de la alocución, es decir, si el producto de la acción va dirigido a individuos (ciudadanía/receptores), o bien a otros actores o grupos a los que se desea neutralizar con determinada declaración.

También es necesario recordar con Goffman, que el actor social define su actuación con referencia a un rol, de manera que se espera que ciertas acciones o expresiones se conviertan en el producto natural de un determinado actor. Cuando la expresión o declaración de un actor es consistente con el desempeño de su rol, resulta entonces natural que sus manifestaciones se difundan en medios que coincidan con su postura, mientras que lo verdaderamente noticioso sería que una expresión, declaración o manifestación fuese contraria a lo que esperado en función de un rol. Así por ejemplo, en el caso de expresiones de actores políticos, se espera que éstas se den en función de la ideología que representan o con la cual comulgan, mientras que también se espera que la expresión de actores institucionales sea mucho más moderada o neutral en concordancia con la idea de la neutralidad de las instituciones como estabilizadoras del todo social.

Los resultados arrojados por esta investigación demuestran cómo la mayor parte de las declaraciones están ubicadas en actores de tipo político o educativo, mientras que las declaraciones a favor pertenecen a actores del ámbito empresarial, lo cual desde luego sería consistente con lo esperado por la teoría en concordancia con el rol. No obstante, es importante mencionar que la concordancia en expresiones de tipo político no necesariamente aparece en concordancia con la filiación partidista de los actores políticos registrados, lo cual pone de manifiesto una pluralidad política al interior del grupo que se manifestó específicamente en contra de la ley en cuestión.

Por otra parte también es importante mencionar que la presencia de las declaraciones puede haber sido consecuencia de las acciones estratégicas emprendidas por ciertos actores o grupos, para buscar y asegurar su presencia en medios o su visibilidad en el escenario, acciones de las cuales desde luego no tenemos evidencia, pero que de manera natural existen como precondición para la acción en términos de la teoría goffmaniana (Goffman, 1974), según la cual el actor prepara y asegura una actuación en el escenario, define las condiciones de su representación, se asegura del apoyo entre bastidores, planea y ensaya la ejecución de un rol, y define la distancia de rol en la que el actor se sitúa por referencia con otros en el escenario. En muchos sentidos entonces, los espectadores esperan cierta ejecución por parte de los actores que salen a escena, asumiendo que la ejecución de su rol y la maestría de su representación, les va

\author{
El proceso de discusión de la Ley Federal de Radio, Televisión • 55 \\ y Telecomunicaciones en el contexto de la Teoría de la Acción Social
}


a permitir comprender las diferentes posiciones protagónicas y antagónicas ante una problemática determinada, presentando así la fuerza esencial necesaria para la interpretación de las normas que rigen al todo social. Así pues, cuando el espectador no logra ver en el actor una posición clara, desestima su actuación o la considera contraria a su rol, valorándola así como poco convincente o útil para llevar adelante una interpretación fiable. Una audiencia que no recibe una interpretación confiable de un rol, ya sea porque los actores no son convincentes en su papel, o porque la trama está mal planteada, podrá entonces confundir los distintos planteamientos, quedar desinformada respecto de la precisión de las posiciones, o perder en general el interés por la puesta en escena, desestimando finalmente el valor general de la obra como asunto de trascendencia social.

En el caso de un asunto como éste, en que la discusión sobre la Ley Federal de Radio, Televisión y Telecomunicaciones está inconclusa, la interpretación que los espectadores pueden hacer es que se trata de una expresión más de otra discusión inacabada en donde la oposición juega el papel de la oposición mientras que las instituciones empresariales y mediáticas juegan el suyo, pero que en términos generales estamos ante una autorrepresentación y autorreproducción de un sistema de sentido pre-existente, que no va a cambiar y en donde no está claro cuál será el detonador que desenmarañará el nudo para que se propicie un desenlace. En otras palabras, así como en cualquier obra de teatro, hay momentos climáticos en los que cada actor define su posición y otros en los que se presenta un enfrentamiento, de la misma manera en la discusión hubo momentos, definidos por los plazos de votación, publicación y amparo en contra de la resolución de la ley, que fueron los que privilegiaron los medios a fin de presentar las diversas posiciones; sin embargo, a menos que se presente otro momento crucial en el que los actores sean obligados a definir y enfrentar nuevamente sus posturas, los medios dejarán de darles presencia. Ahora bien, en este juego de visibilidades cabe la posibilidad, como acción entre bastidores, de que algunos actores hagan lo posible por mantener a la obra y a su desenlace en suspenso, mientras que otros luchen por llevarla a término. La probabilidad de que un actor domine dependerá desde luego, de su posición social y del estatus del cual goce dentro de la obra. Ya Gitlin criticaba en su momento las prácticas retóricas tanto de la izquierda como la derecha que finalmente cuando son plasmadas en los medios de comunicación, acaban dibujando una caricatura de los acontecimientos (Gitlin, 1980). Y es que en general, diría Luhmann, cualquier sistema social tiende a clausurar operativamente y de forma autopoiética, cualquier elemento que le impide su 
reestablecimiento; de manera que ningún elemento exógeno es introducido, a menos que se garantice que la nueva relación entre elementos pueda garantizar el equilibrio (Luhmann, 2005).

\section{Conclusiones}

Los resultados de este trabajo indican que las expresiones relativas a la ley se centraron en argumentos negativos siendo éste el escenario preferente que los medios enmarcaron la discusión sobre el tema.

Las argumentaciones y la frecuencia de las notas periodísticas recabadas, muestran la evidencia preferente de la participación política directa de actores y medios específicos en concordancia con su orientación política y con la definición predefinida de su rol.

Los datos y la forma en la que fueron recabados no nos permiten conocer las acciones ejercidas tras bastidores, ni los criterios asumidos por los medios para la difusión preferente o no de ciertas informaciones pero sí conocer los períodos de tiempo en los que la nota fue difundida, lo cual es consistente con hallazgos anteriores que corroboran la existencia ciertas prácticas periodísticas responsables de la conformación social a partir del establecimiento de la agenda. Sin embargo, queda pendiente para futuras investigaciones, un análisis de la percepción de la opinión pública en la construcción de una determinada opinión sobre el particular a partir de la presentación de escenarios y la forma en que se favorece en los receptores de los medios una cierta interpretación de los asuntos que son vitales para la gestión de políticas públicas y en particular en este caso para el resultado de la discusión sobre políticas de comunicación y telecomunicaciones.

\section{REFERENCIAS}

Alva de la Selva, A. (2008). "Del recorrido hacia una reforma democrática de los medios: Las aportaciones de la Iniciativa Ciudadana” En: A. Vega, M. Portillo y J. Repoll (coords.). Las claves necesarias de una comunicación para la democracia. México: AMIC/Universidad Juárez Autónoma de Tabasco.

Bateson, G. (1972). Steps to Ecology of Mind: Collected Essays in Anthropology, Psychiatry, Evolution and Epistemology. Chicago: University of Chicago Press.

Durkheim, E. (1964). Las reglas del método sociológico. Buenos Aires: Dédalo.

Flores, R. (1997). Alcances para una conceptualización constructivista del concepto de acción social. Cintia de Moebio, diciembre, número 2, Santiago: Universidad de Chile.

El proceso de discusión de la Ley Federal de Radio, Televisión • 57 y Telecomunicaciones en el contexto de la Teoría de la Acción Social 
Giddens, A. (1984). The Constitution of Society: Outline of Theory of Structuration. California: University of California Press.

Gitlin, T. (1980). The Whole World is Watching: Mass Media in the Making and Unmaking of The New Left. California: University of California Press.

Goffman, E. (1959). The Presentation of Self in Everyday Life. New York: Doubleday Anchor Books.

Goffman, E. (1961). Encounters: Two Studies in the Sociolgy of Interaction. Indianapolis: Bobbs Merril.

Goffman, E. (1981). Forms of Talk. Philadelphia: University of Pennsylvania Press.

Luhmann, N. (2005). Organización y decisión: autopoiesis, acción y entendimiento comunicativo. Barcelona: Anthropos; México, D.F.: Universidad Iberoamericana; Santiago de Chile: Pontificia Universidad Católica.

Luhmann, N. (1990). Essays on Self-Reference. New York: Columbia University Press.

Luhmann, N. (1982). Autopoiesis, Acción y Entendimiento Comunicativo. En: Zeitschrift für Sociologie. Año 11, No 4, octubre. pp. 366-379. Traducción de Darío Rodríguez.

Manning, P. (1989). Erving Goffman and Modern Sociology. Cambridge: Polity Press.

McCombs, M. \& Shaw, D. (1972). The Agenda-Setting Function of Mass Media. The Public Opinion Quarterly, 36 (2), 176-187.

Merton, R. (1968). Social Theory and Social Action. New York: The Free Press.

Parsons, T. (1988). The Structure of Social Action. New York: McGraw Hill.

Parsons, T. (1951). The Social System. Glencoe: Free Press.

Rodrigo Alsina, M. (1989). La construcción de la noticia. Barcelona: Paidós.

Sebastián de Erice, J. (1994). Erving Goffman. De la interacción focalizada al orden interaccional. Madrid: CIS.

SCJN (2007). Decreto por el que se reforman, adicionan y derogan diversas disposiciones de la Ley Federal de Telecomunicaciones y de la Ley Federal de Radio y Televisión. Aclaración de sentencia de la Suprema Corte de Justicia de la Nación. Diario Oficial de la Federación. Viernes 19 de octubre de 2007.

Tankard, J. (1991). Media Frames: Approaches to Conceptualization and Measurement. Paper presented at the Education in Journalism and Mass Communication Convention, Boston.

Touraine, A. (1977). The Self-Production of Society. Chicago: University of Chicago Press.

Tuchman, G. (1983), La producción de la noticia: Estudio sobre la construcción de la realidad. Barcelona: Gustavo Gili.

Van Dijk, T. (1985). Handbook of Discourse. London: Academic Press.

Van Dijk, T. (1999). Ideología: Un enfoque multidisciplinario. Barcelona: Gedisa.

Verón, E. (1995). Construir el acontecimiento: los medios de comunicación masiva y el accidente nuclear de Three Mile Island. Barcelona: Gedisa.

Weber, M. (1977). Economía y sociedad. México: Fondo de Cultura Económica. 